\title{
Field calibration of DFM capacitance probes for continuous soil moisture monitoring
}

\author{
L Myeni ${ }^{1,2}$, ME Moeletsi ${ }^{1,3}$ and AD Clulow ${ }^{2}$ \\ 'Agricultural Research Council - Institute for Soil, Climate and Water, Private Bag X79, Pretoria 0001, South Africa \\ ${ }^{2}$ Agrometeorology, School of Agricultural, Earth and Environmental Sciences, University of KwaZulu-Natal, Pietermaritzburg, South Africa \\ ${ }^{3}$ Risks and Vulnerability Assessment Centre, University of Limpopo, Private Bag X1106, Sovenga, 0727, South Africa
}

This study was undertaken to derive textural and lumped site-specific calibration equations for Dirk Friedhelm Mercker (DFM) capacitance probes and evaluate the accuracy levels of the developed calibration equations for continuous soil moisture monitoring in three selected soil types. At each site, 9 probes (3 per plot) were installed in $2 \mathrm{~m}^{2}$ plots, for continuous soil moisture measurements at 5 different depths (viz. 10, 20,30, 40 and $60 \mathrm{~cm}$ ) under dry, moist and wet field conditions. Textural site-specific calibration equations were derived by grouping the same soil textural classes of each site regardless of soil depth, while lumped site-specific calibration equations were derived by grouping all datasets from each site, regardless of soil depth and textural classes. Sensor readings were plotted against gravimetrically measured volumetric soil moisture $\left(\theta_{v}\right)$ for different textural classes as a reference. The coefficient of determination $\left(r^{2}\right)$ was used to select the best fit of the regression function. The developed calibration equations were evaluated using an independent dataset. The results indicated that all developed textural and lumped site-specific calibration equations were linear functions, with $r^{2}$ values ranging from 0.96 to 0.99 . Relationships between the measured and estimated $\theta_{v}$ from calibration equations were reasonable at all sites, with $r^{2}$ values greater than 0.91 and root mean square error (RMSE) values ranging from 0.010 to $0.020 \mathrm{~m}^{3} \cdot \mathrm{m}^{-3}$. The results also indicated that textural site-specific calibration equations (RMSE $<0.018 \mathrm{~m}^{3} \cdot \mathrm{m}^{-3}$ ) should be given preference over lumped site-specific calibrations (RMSE $<0.020 \mathrm{~m}^{3} \cdot \mathrm{m}^{-3}$ ) to attain more accurate $\theta_{v}$ measurements. The findings of this study suggest that once DFM capacitance probes are calibrated per site, they can be reliably used for accurate in-situ soil moisture measurements. The developed calibration equations can be applied with caution in other sites with similar soil types to attained reliable in-situ soil moisture measurements.

\section{INTRODUCTION}

The need for accurate soil moisture estimates at high temporal and spatial resolution is becoming more urgent to support efficient water management, agricultural productivity, drought management and flood forecasting within the context of climate change modelling and adaptation (Pegram et al., 2010; Seneviratne et al., 2010; Ojo et al., 2015b; Tfwala et al., 2019a). Consequently, there has been a dramatic increase in the number of remote-sensing products and hydrological models to estimate soil moisture instantaneously at high temporal and spatial resolution (e.g. Gruhier et al., 2010; Pegram et al., 2010; Amri et al., 2012). However, their estimates still need to be calibrated and validated using in-situ soil moisture measurements, which are thought to be more accurate (Walker et al., 2004; Dobriyal et al., 2012; Brocca et al., 2017). Therefore, the need for accurate in-situ soil moisture measurements at a high temporal and spatial resolution within the context of evaluation and verification of soil moisture estimates cannot be overemphasized (Zreda et al., 2012; Gruber et al., 2013; Ojo et al., 2015b; Brocca et al., 2017; Holzman et al., 2017).

In recent years, numerous studies have been instituted in various countries to establish in-situ soil moisture monitoring networks (e.g. Dorigo et al., 2011; Albergel et al., 2012; Pan et al., 2012; Zreda et al., 2012; Diamond et al., 2013). Datasets from most of these networks have been merged in the International Soil Moisture Network (ISMN) and are freely available on their website (https://ismn. geo.tuwien.ac.at/) (Dorigo et al., 2011; Albergel et al., 2012; Zreda et al., 2012; Gruber et al., 2013) to support the calibration, validation and improvement of soil moisture estimations. In most of these networks, soil moisture is often measured indirectly with dielectric sensors which are based on time domain reflectometry (TDR) and frequency domain reflectometry (FDR) or capacitance principles (Dorigo et al., 2011; Pan et al., 2012; Gruber et al., 2013; Ojo et al., 2015b; Holzman et al., 2017).

Multi-depth capacitance sensors have become the most popular devices for real-time, continuous and non-destructive soil moisture profile measurements, due to their lower cost compared to TDR (Bello et al., 2019; Dhakal et al., 2019; Hajdu et al., 2019; Kassaye et al., 2019; Tfwala et al., 2019a). Capacitance sensors measure the apparent dielectric permittivity of the soil, which is much lower than that of water, such that the output is related to the volumetric moisture content in the soil $\left(\theta_{\mathrm{v}}\right)$, via either the manufacturer's default calibration equation or a user's site-specific calibration equation (Cobos and Chambers, 2010; Gabriel et al., 2010; Archer et al., 2016; Parvin and Degré, 2016).

A generalized calibration equation, relating the relative sensor output to $\theta_{v}$, which is often supplied by the manufacturer, provides an accuracy of $\pm 3 \%$ for typical soils, depending on the specific type of sensor (Cobos and Chambers, 2010). However, irrespective of the stipulated accuracy level claimed by the manufacturers, capacitance probes have been reported to require calibration for different soil types

\section{CORRESPONDENCE}

L Myeni

\section{EMAIL}

lindomyeni@gmail.com

\section{DATES}

Received: 27 November 2019

Accepted: 14 December 2020

\section{KEYWORDS}

in-situ measurements

modelling

site-specific

soil texture

validation

\section{COPYRIGHT}

(c) The Author(s)

Published under a Creative

Commons Attribution 4.0

International Licence

(CC BY 4.0) 
to attain accurate soil moisture measurements, with errors being reduced to $\pm 1 \%$ (Fares et al., 2011; Kinzli et al., 2011; Paraskevas et al., 2012; Bogena et al., 2017; Bello et al., 2019; Hajdu et al., 2019; Kassaye et al., 2019; Tfwala et al., 2019a). Some of the reasons for this observation are due to differences in electrical conductivity and soil dielectric properties (Gabriel et al., 2010; Kinzli et al., 2011). Capacitance probes can be calibrated in the laboratory or in the field for specific textural classes, irrespective of site (Gabriel et al., 2010; Zerizghy et al., 2013; Bello et al., 2019; Tfwala et al., 2019a) However, capacitance probes have been reported to have required site-specific calibrations to attain more accurate soil moisture measurements (Fares et al., 2011; Kinzli et al., 2011; Paraskevas et al., 2012; Bogena et al., 2017; Bello et al., 2019; Dhakal et al., 2019; Hajdu et al., 2019; Kassaye et al., 2019; Tfwala et al., 2019a).

Site-specific calibrations that are carried out on specific soil types under specific agro-ecological conditions are more consistent with site measurements (Fares et al., 2011; Kinzli et al., 2011). Sitespecific calibrations take into consideration soil properties such as soil texture, mineralogy, bulk density, salinity, temperature and organic matter of the specific site, that are known to vary with depth and affect the accuracy of the capacitance sensors (Huang et al., 2004; Kizito et al., 2008; Fares et al., 2011; Paraskevas et al., 2012; Hajdu et al., 2019). Site-specific calibration equations are generally derived either through textural or lumped sitespecific calibration equations (Hajdu et al., 2019). The textural site-specific calibration equations take into consideration the variation of soil properties with depth in a specific soil profile (e.g. Da Silva et al., 2007; Fares et al., 2011; Parvin and Degré, 2016; Dhakal et al., 2019). On the other hand, lumped sitespecific calibration equations are derived by grouping all soil textural classes of the specific site regardless of soil depth (Hajdu et al., 2019). Previous studies have indicated that better accuracy of soil moisture measurement can be achieved through textural site-specific calibration of the capacitance probes compared to the lumped site-specific calibration equations (e.g. Da Silva et al., 2007; Parvin and Degré, 2016; Hajdu et al., 2019).

Site-specific calibration equations are generally derived either through laboratory analyses or field techniques, by establishing relationships between the sensor readings and gravimetrically measured $\theta_{v}$ at different moisture levels (Kinzli et al., 2011; Archer et al., 2016; Hajdu et al., 2019). Studies have shown that laboratory calibration equations developed using undisturbed soil samples are more accurate than field calibration equations (e.g., Geesing et al., 2004; Gabriel et al., 2010; Kinzli et al., 2011; Bello et al., 2019; Hajdu et al., 2019; Tfwala et al., 2019a). The high accuracy of laboratory calibration equations over field calibration equations is attributed to the wide range of soil moisture contents, ranging from permanent wilting point to saturation, and a relatively large number of replicates of continuous measurements in the laboratory (Gabriel et al., 2010; Varble and Chávez, 2011; Bello et al., 2019; Tfwala et al., 2019a). Gabriel et al. (2010), Paraskevas et al. (2012) and Tfwala et al. (2019a) calibrated different capacitance probes in the laboratory and were able to use the equation in the field with high accuracy. However, laboratory facilities are costly, and transporting and soil sampling of undisturbed core samples for laboratory studies may alter the soil properties. Furthermore, site-specific calibrations are generally labour-intensive and timeconsuming (Gabriel et al., 2010; Tfwala et al., 2019a). Thus, capacitance sensors are often used without proper site-specific calibration in many in-situ soil moisture monitoring networks, which makes the accuracy of their measurements questionable (Gruber et al., 2013; Poltoradnev et al., 2014; Ojo et al., 2015b).

The Agricultural Research Council (ARC) of South Africa is running a project to monitor soil moisture at various sites across the country and to archive the information for potential agricultural use (Moeletsi et al., 2009). Soil moisture monitoring is currently carried out with the use of Dirk Friedhelm Mercker (DFM) capacitance probes (DFM Software Solutions, 2015). However, these probes have been installed without prior textural or site-specific calibrations. To this end, the monitoring network has about 5 years of continuous datasets acquired from 17 stations, distributed across all agro-climatic zones of South Africa. This raises the following questions: how accurate is the output of the probes, and how well can the datasets from these probes be trusted and used as in-situ $\theta_{v}$ ?

In South Africa, DFM recently introduced a multifunctional capacitance soil probe, hereafter named DFM capacitance probe, that can measure soil moisture content and temperature simultaneously (DFM Software Solutions, 2015). This device has been widely accepted by farmers and in the past 3 years, 15000 units were sold in South Africa, with 14250 going to the agriculture sector and 750 for research purposes (Mjanyelwa et al., 2016). The advantage of this device is that it can measure at multi-depth - normally 6 depths in a soil profile. It is userfriendly, portable, cheap and easy to maintain (Mjanyelwa et al., 2016; Zerizghy et al., 2013). In terms of user-friendliness, the output of the probes is a percentage (\%), which farmers can more easily relate to than frequency, millivolts or counts. At this point, it is worth mentioning that calibration and validation of DFM capacitance probe measurements under field conditions has received little scientific attention, although they have been utilized in some scientific studies. For example, Zerizghy et al. (2013) calibrated DFM probes under laboratory conditions using the repacked Bainsvlei topsoil, while in other studies the probes were used directly without reporting their calibration under field conditions (Roets et al., 2013; Tfwala et al., 2019b). Therefore, there is a need to evaluate the performance of DFM capacitance probes in a wide range of soil types, before they can be utilized for reliable and continuous in-situ soil moisture measurements.

Calibration of the DFM capacitance probes of the ARC is required to improve the confidence with which the soil moisture data can be used. The objectives of this study were to develop textural and lumped site-specific calibration equations for DFM capacitance probes and to evaluate the accuracy levels of the developed calibration equations for continuous soil moisture monitoring in three selected soil types, in different agro-climatic zones of South Africa. Due to the range of soil types used in this study, it is assumed that the derived calibration equations can be applied with caution in other sites with similar soil types to attained reliable in-situ soil moisture measurements.

\section{MATERIALS AND METHODS}

\section{Study site description}

The study was conducted at three automatic weather stations, located at Bainsvlei (in Free State), Bronkhorstspruit (in Gauteng) and Mandeni (in KwaZulu-Natal), which represent a wide range of soil types and agro-climatic zones found in South Africa (Table 1). The choice of stations was also based on the completeness ( $<10 \%$ missing data) of the ARC soil moisture dataset. Although all stations were within agricultural cropping areas, the stations were in flat grassland (slope $<2 \%$, data not presented here). Each site had a weather station equipped with a rain gauge, solar radiation, air temperature and relative humidity, wind speed and wind direction sensors as well as a DFM capacitance probe for that location. The soil at the Bainsvlei station was classified as Rhodic Ferralsols (IUSS Working Group, 2014), which is locally known as the Hutton soil form (Soil Classification Working Group, 1991). The soil at the Bronkhorstspruit station was classified as Glossic Leptosols (IUSS Working Group, 2014), which is locally known as the Glenrosa soil form (Soil Classification Working Group, 1991). 
Table 1. Characteristics of three sites used

\begin{tabular}{lccccl}
\hline Station name & Latitude $\left(^{\circ}\right)$ & Longitude $\left(^{\circ}\right)$ & Elevation $(\mathrm{m}$ amsl) & Soil form & Climate conditions \\
\hline Bainsvlei & -29.146 & 26.146 & 1290 & Hutton & Arid, steppe and cold arid \\
Bronkhorstspruit & -25.702 & 28.799 & 1500 & Glenrosa & Warm temperate, dry winter and warm summer \\
Mandeni & -29.156 & 31.344 & 107 & Namib & Warm temperate, fully humid and hot summer \\
\hline
\end{tabular}

Soil classification was based on the Soil Classification Working Group (1991) and the description of climatic conditions was based on the Köppen-Geiger climate classification of Conradie (2012)

The soil at the Mandeni station was classified as Arenic Arenosols (IUSS Working Group, 2014), which is locally known as the Namib soil form (Soil Classification Working Group, 1991).

\section{Description of the DFM capacitance probe}

DFM capacitance probes are multi-depth sensors that measure soil moisture and temperature continuously and simultaneously at 6 depths in a soil profile (Fig. 1). The sensing radius of the DFM capacitance probe is $10 \mathrm{~cm}$ (DFM Software Solutions, 2015). DFM capacitance probes are equipped with small solar panels and rechargeable batteries, and have PVC caps that protect the electronics, and hence are suitable for continuous soil moisture monitoring under severe weather conditions (DFM Software Solutions, 2015). The DFM capacitance probe is a stand-alone sensor with a datalogger that can store data at different time

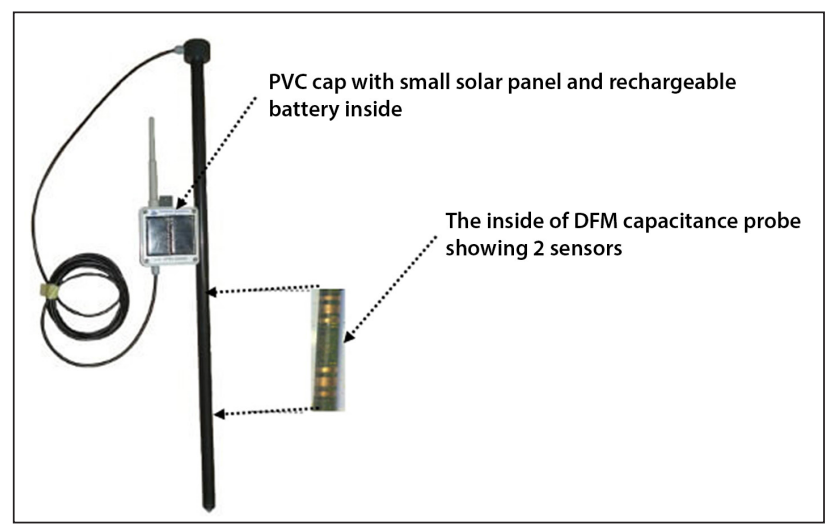

Figure 1. DFM capacitance probe with 6 sensors inside a tube $80 \mathrm{~cm}$ long (adapted from DFM Software Solutions, 2015) intervals for more than 60 days. Stored data can be displayed and downloaded onto a computer, either in the field or in the office, using DFM software (DFM Software Solutions, 2015).

\section{Calibration procedure}

\section{Experimental layout and moisture regimes}

At each site, three sampling plots of $2 \mathrm{~m}^{2}$ were demarcated approximately $2 \mathrm{~m}$ away from the ARC's existing DFM capacitance probe, to prevent any possible damage to their sensors (Fig. 2a). The soil, vegetation and slope characteristics at the pits were the same as the existing ARC probe sites (Fig. $2 \mathrm{~b}$ ). These plots were constructed by forming soil ridges around the plot boundaries to allow ponding of water on the surface during the wetting process. Within each plot, three DFM capacitance probes were installed approximately $1 \mathrm{~m}$ apart in a triangular configuration (Fig. 2c) for continuous soil moisture measurements at 5 different depths (viz. $10,20,30,40$ and $60 \mathrm{~cm}$ ), following the manufacturer's installation recommendations (DFM Software Solutions, 2015). Two pits of approximately $0.4 \mathrm{~m}$ wide and $0.8 \mathrm{~m}$ deep were dug between the three plots for soil dry bulk density $\left(\rho_{\mathrm{d}}\right)$ core sampling at different moisture levels (Fig. 2d). Although these pits were at the fringes of the plots, they represent soil moisture levels within the plots.

The surfaces of wet and moist plots were uniformly filled with water using water tanks to near saturation while the moist plot was filled with half the total volume of water used in the wet plot. All plots were then covered immediately by sackcloth bags to minimize evaporation, and left for about 2 weeks to allow water to infiltrate and redistribute within the soil profile in both the moist and wet plots while allowing the dry plot to remain un-watered (Fig. 2a). A 2-week period allowed the probes to stabilize within the soil for reliable soil moisture measurements.

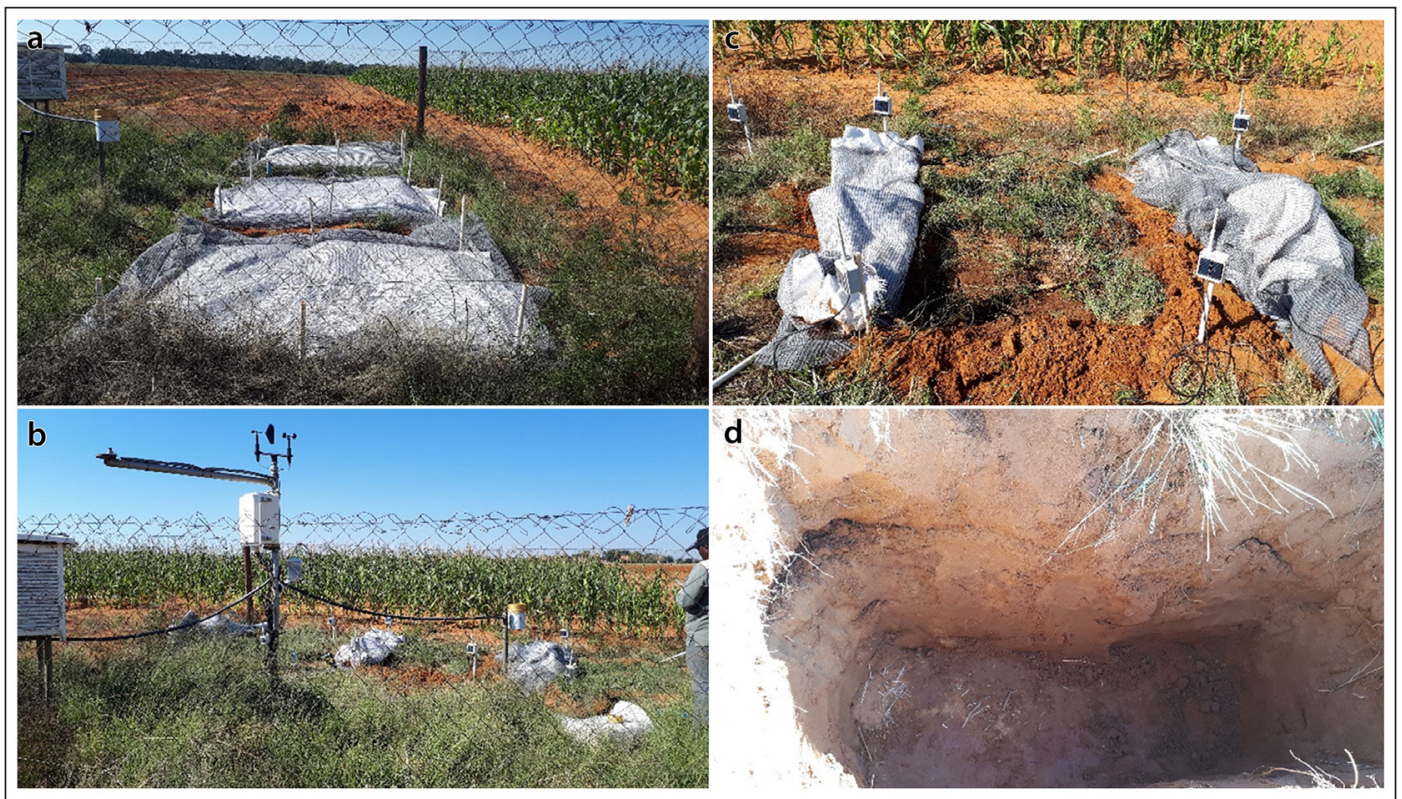

Figure 2. Experimental layout at the Bainsvlei site during the calibration process of DFM capacitance probes (a), soil, vegetation and slope characteristics at the plots were the same as for the existing ARC probe (b), 3 probes installed in a wet plot (c), $0.4 \mathrm{~m}$ wide and $0.8 \mathrm{~m}$ deep pit for bulk density sampling (d) 


\section{Soil sampling}

After 2 weeks, three gravimetric samples, at each of the depths corresponding to the depths of sensors on the DFM capacitance probes installed within the plots, were collected using a soil auger. Although the sampling radius (approximately $30 \mathrm{~cm}$ ) was beyond the sphere of influence of the probe $(10 \mathrm{~cm})$ to prevent any possible damage to the sensor and cables, it could still be regarded as a representative measurement of the soil moisture (Kinzli et al., 2011). The time of sampling and probe numbers were recorded. After sampling, the wet plot was then uniformly refilled with water to near saturation while the moist plot was filled with half the total volume of water used in the wet plot, following the procedure of Hajdu et al. (2019). After the ponded water had infiltrated, the wet and moist plots were covered immediately to minimize evaporation. Approximately $2 \mathrm{~h}$ was allowed for the water to infiltrate and redistribute within the soil profile, while the dry plot was left open to air dry throughout the calibration process. Once the sensor outputs were stable, three gravimetric soil samples at each of the depths corresponding to the sensors on the installed DFM capacitance probes were collected using a soil auger. Undisturbed soil samples for $\rho_{\mathrm{d}}$ were collected from the pits using $98 \mathrm{~cm}^{3}$ steel cylinders, and the time of sampling was recorded. All plots were then allowed to air dry further and the sampling process was repeated every $2 \mathrm{~h}$ while drying took place. This cycle of wetting, taking gravimetric and $\rho_{\mathrm{d}}$ samples while recording time of sampling as the plots were air-dried, was repeated for 3 days to get a wide range of soil moisture statuses for calibration. All the collected soil samples were immediately weighed in the field to determine their initial weights and reweighed after oven-drying at $105^{\circ} \mathrm{C}$ for $48 \mathrm{~h}$ to determine gravimetric soil moisture content $\left(\theta_{\mathrm{g}}\right)$. In addition, 3 replicates of bulk soil samples were also collected from the same depths at each site using a soil auger and mixed thoroughly to make a composite sample of $5 \mathrm{~kg}$ for each depth. Composite soil samples were transported to the ARC laboratory to determine particle size distribution, electric conductivity (EC) and organic carbon content (OC) for each depth. The textural triangle of the United States Department of Agriculture (USDA) classification scheme of Gee and Bauder (1986) was then used to determine the soil textural class for each depth.

\section{Data collection and processing}

Sensor outputs during the calibration period from each probe were extracted from the ARC databank. The recorded time of sampling and probe numbers were then used to match $\theta_{\mathrm{g}}$ and the corresponding sensor reading. The bulk density of each soil depth was used to convert the corresponding $\theta_{\mathrm{g}}$ to $\theta_{\mathrm{v}}$. All data underwent a quality control routine to identify errors to ensure that the data were consistent. For example, an average of either 2 or 3 replicates that had less than a $10 \%$ difference was used as a single data point. Unreasonable $\theta_{v}$ measurements and sensor readings (\%) were discarded, resulting in a relatively low number of observations. Errors in $\theta_{\mathrm{v}}$ measurements were attributed to the non-uniform distribution of water within the sampling plots and the presence of stones in some samples. On the other hand, errors in sensor readings were due to either non-response or response with inconsistent values amongst replicates that were attributed to the sensor production process, as also noted by Bello et al. (2019).

\section{Calibration and validation of DFM capacitance probes}

For each site, the same soil textural classes were grouped, regardless of soil depth, and then divided in half, with one half used for the development of a textural site-specific calibration equation and the other for validation of the developed equation.
In addition, all datasets from each site were grouped, regardless of soil depth and textural class, and then divided in half, with one half used for the development of a lumped site-specific calibration equation and the other for validation of the developed equation. All calibration equations were developed by plotting sensor outputs against corresponding $\theta_{\mathrm{v}}$ measurements. The accuracy of the developed calibration equations was evaluated using an independent dataset, by comparing gravimetrically measured and estimated $\theta_{v}$ from calibration equations using corresponding sensor outputs.

\section{Statistical analysis}

The coefficient of determination $\left(r^{2}\right)$ was used to select the best fit of the regression function during the development of calibration equations (Bello et al., 2019; Hajdu et al., 2019; Tfwala et al., 2019a). The root mean square error (RMSE), mean bias error (MBE) and index of agreement $(d)$ were used to evaluate the performance of the calibration equations and were calculated based on Willmott et al. (1985) as:

$$
\begin{gathered}
R M S E=\sqrt{\frac{\sum_{i=1}^{n}\left(\theta_{\mathrm{ve} i}-\theta_{\mathrm{v} i}\right)^{2}}{n}} \\
\mathrm{MBE}=\frac{\sum_{i=1}^{n}\left(\theta_{\mathrm{ve} i}-\theta_{\mathrm{v} i}\right)}{n} \\
d=1-\left[\frac{\sum_{i=1}^{n}\left(\theta_{\mathrm{ve} i}-\theta_{\mathrm{v} i}\right)^{2}}{\sum_{i=1}^{n}\left(\theta_{\mathrm{ve} i}-\overline{\theta_{\mathrm{v}}}|+| \theta_{v i}-\overline{\theta_{\mathrm{v}}} \mid\right)^{2}}\right.
\end{gathered}
$$

where $i$ is the data pair index, $\theta_{\mathrm{ve}}$ is the estimated volumetric moisture content from the DFM probes, $\theta_{\mathrm{v}}$ is the observed volumetric moisture content, $\bar{\theta}_{\mathrm{v}}$ is the mean of all observations of $\theta_{\mathrm{v}}$ and $n$ is the number of observations. A linear regression between $\theta_{\mathrm{ve}}$ and $\theta_{\mathrm{v}}$ values was also computed:

$$
\theta_{\mathrm{ve}}=m \theta_{\mathrm{v}}+c
$$

where the slope $(m)$ was used as a measure of accuracy and $c$ is the y-intercept. The coefficient of determination $\left(r^{2}\right)$ was used as a measure of precision. According to Willmott et al. (1985) for the best model performances, RMSE, MBE and $c$ values should approach zero whilst $d, r^{2}$ and $m$ values should approach 1 .

\section{RESULTS AND DISCUSSION}

\section{Soil physical and chemical properties}

A summary of the physical and chemical properties that affect soil moisture measurement accuracy illustrated the wide range of textural classes across the study sites (Table 2). The results of the soil analysis showed that the Bainsvlei site was dominated by sand $(0-40 \mathrm{~cm})$, while sandy loam was found only from $40 \mathrm{~cm}$ depth, indicating homogeneity of the soil profile. The Bronkhorstspruit site had sandy topsoil $(0-10 \mathrm{~cm})$ and was dominated by loamy sand $(20-40 \mathrm{~cm})$, while sandy loam was only found from $40 \mathrm{~cm}$, indicating heterogeneity of the soil profile. The Mandeni site had only sand $(0-60 \mathrm{~cm})$, indicating homogeneity of the soil profile. The clay content, $\rho_{\mathrm{d}}$ and OC of the soils increased with depth at all sites as expected (Bello et al., 2019; Hajdu et al., 2019). The results further showed that the Bronkhorstspruit site had the highest bulk densities compared to the other sites. Soil properties such as $\rho_{\mathrm{d}}$, EC, $\mathrm{pH}$ and OC were within the expected range for each soil textural class (Ersahin et al., 2006; Bello et al., 2019). 
Table 2. Selected physical and chemical properties of the study sites

\begin{tabular}{|c|c|c|c|c|c|c|c|c|c|}
\hline Site & Textural class & $\begin{array}{c}\text { Depth } \\
(\mathrm{cm})\end{array}$ & $\begin{array}{c}\text { Sand } \\
(\%)\end{array}$ & $\begin{array}{l}\text { Silt } \\
(\%)\end{array}$ & $\begin{array}{l}\text { Clay } \\
(\%)\end{array}$ & $\begin{array}{c}\rho_{\mathrm{d}} \\
\left(\mathrm{g} \cdot \mathrm{cm}^{-3}\right)\end{array}$ & $\begin{array}{c}E C \\
\left(\mathrm{mS} \cdot \mathrm{m}^{-1}\right)\end{array}$ & $\begin{array}{c}\mathrm{pH} \\
(\mathrm{KCl})\end{array}$ & $\begin{array}{l}\text { OC } \\
(\%)\end{array}$ \\
\hline \multirow[t]{2}{*}{ Bainsvlei } & Sand & $0-40$ & 95 & 2 & 3 & 1.64 & 5.53 & 5.01 & 0.76 \\
\hline & Sandy loam & $40-60$ & 81 & 2 & 17 & 1.78 & 8.36 & 5.70 & 0.75 \\
\hline \multirow[t]{3}{*}{ Bronkhorstspruit } & Sand & $0-10$ & 89 & 6 & 5 & 1.58 & 7.73 & 4.30 & 1.29 \\
\hline & Loamy sand & $20-40$ & 84 & 4 & 12 & 1.80 & 7.03 & 4.43 & 0.87 \\
\hline & Sandy loam & $40-60$ & 77 & 15 & 8 & 1.84 & 3.82 & 4.60 & 0.27 \\
\hline Mandeni & Sand & $0-60$ & 96 & 4 & 0 & 1.57 & 7.79 & 5.51 & 0.84 \\
\hline
\end{tabular}

where $\rho_{d}$ is the soil dry bulk density, EC is the electric conductivity and OC is the organic carbon content

Table 3. Textural and lumped site-specific calibration equations for DFM capacitance probes with their statistical indicators

\begin{tabular}{|c|c|c|c|c|c|c|}
\hline Site & Textural class & $n$ & Regression type & Calibration equation & $r^{2}$ & $p$ \\
\hline \multirow[t]{3}{*}{ Bainsvlei } & Sand & 42 & Linear & $\theta_{v}=0.0053 x-0.0153$ & 0.97 & $<0.001$ \\
\hline & Sandy loam & 23 & Linear & $\theta_{v}=0.0056 x-0.0221$ & 0.96 & $<0.001$ \\
\hline & Lumped site-specific & 65 & Linear & $\theta_{v}=0.0054 x-0.0155$ & 0.96 & $<00001$ \\
\hline \multirow[t]{4}{*}{ Bronkhorstspruit } & Sand & 12 & Linear & $\theta_{v}=0.004 x+0.0743$ & 0.97 & $<0.001$ \\
\hline & Loamy sand & 12 & Linear & $\theta_{v}=0.0034 x+0.0878$ & 0.99 & $<0.001$ \\
\hline & Sandy loam & 12 & Linear & $\theta_{v}=0.0035 x+0.0834$ & 0.98 & $<0.001$ \\
\hline & Lumped site-specific & 36 & Linear & $\theta_{v}=0.0035 x+0.084$ & 0.96 & $<0.001$ \\
\hline \multirow[t]{2}{*}{ Mandeni } & Sand & 40 & Linear & $\theta_{v}=0.0038 x-0.0615$ & 0.99 & $<0.001$ \\
\hline & Lumped site-specific & 40 & Linear & $\theta_{v}=0.0038 x-0.0615$ & 0.99 & $<0.001$ \\
\hline
\end{tabular}

where $\mathrm{n}$ is the number of observations and $\mathrm{x}(\%)$ is the sensor output

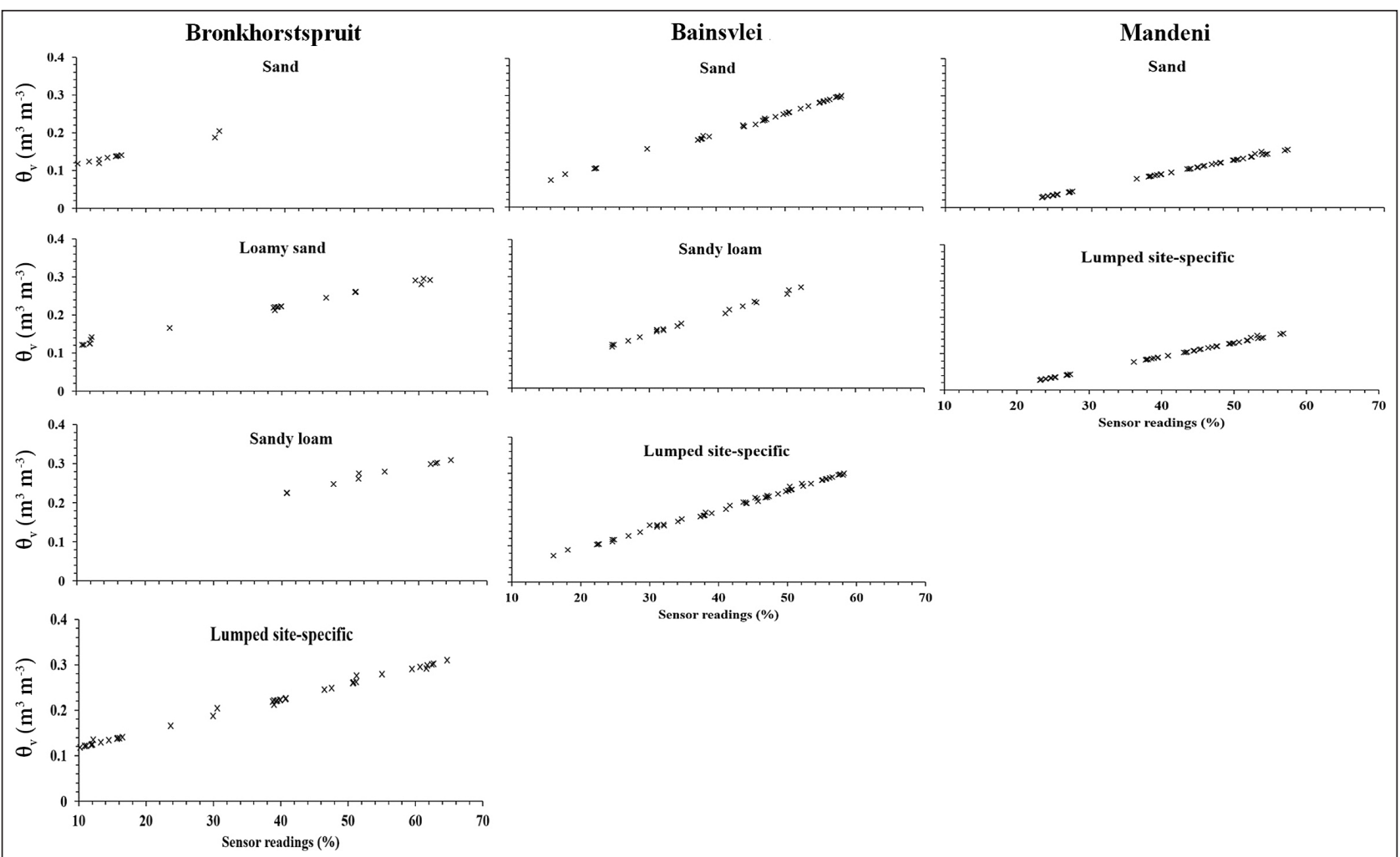

Figure 3. Relationships between sensor outputs of the DFM capacitance probes and volumetric water content for different soil textural classes and sites

\section{Calibration of DFM capacitance probes}

At the Bronkhorstspruit site, measured $\theta_{\mathrm{v}}$ ranged from 0.11 to $0.20 \mathrm{~m}^{3} \cdot \mathrm{m}^{-3}$ (sand), 0.12 to $0.29 \mathrm{~m}^{3} \cdot \mathrm{m}^{-3}$ (loamy sand), 0.23 to $0.31 \mathrm{~m}^{3} \cdot \mathrm{m}^{-3}$ (sandy loam) and 0.11 to $0.31 \mathrm{~m}^{3} \cdot \mathrm{m}^{-3}$ for all collected samples (Fig. 3). At the Bainsvlei site, measured $\theta_{\mathrm{v}}$ ranged from 0.04 to $0.30 \mathrm{~m}^{3} \cdot \mathrm{m}^{-3}$ (sand), 0.11 to $0.27 \mathrm{~m}^{3} \cdot \mathrm{m}^{-3}$ (sandy loam), and 0.04 to $0.30 \mathrm{~m}^{3} \cdot \mathrm{m}^{-3}$ for all collected samples. At the Mandeni site, measured $\theta_{\mathrm{v}}$ ranged from 0.03 to $0.15 \mathrm{~m}^{3} \cdot \mathrm{m}^{-3}$ for all collected samples. Despite attempts made in this study to fill the soil profile uniformly with water to near saturation, measurements of $\theta_{v}$ were not greater than $0.31 \mathrm{~m}^{3} \cdot \mathrm{m}^{-3}$ at any of the sites and the lowest $\theta_{\mathrm{v}}$ values were observed at the Mandeni site. The relatively low $\theta_{\mathrm{v}}$ could be attributed to the low water-holding capacity of sandy soils, which dominated all the sites (Ojo et al., 2015a; Bello et al., 2019; Tfwala et al., 2019a). Therefore, measured $\theta_{v}$ results are typical for the range expected for the site soil textural class, as was also noted by Ojo et al. (2015a). Linear relationships were found between sensor outputs (\%) and measured $\theta_{\mathrm{v}}$ for all textural classes at all sites and were statistically significant $(p<0.0001)$, with $r^{2}$ values ranging from 0.96 to 0.99 (Table 3). 


\section{Validation of DFM capacitance probes}

The results indicate that relationships between measured $\theta_{v}$ and $\theta_{v}$ estimated from calibration equations were reasonable at all sites, with $r^{2}$ values greater than 0.91 and $c$ values less than $0.051 \mathrm{~m}^{3} \cdot \mathrm{m}^{-3}$ for all calibration equations (Fig. 4; Table 4). The RMSE values ranged from 0.010 to $0.018 \mathrm{~m}^{3} \cdot \mathrm{m}^{-3}$ with $\mathrm{MBE}$ values ranging from -0.003 to $0.016 \mathrm{~m}^{3} \cdot \mathrm{m}^{-3}$, indicating that all developed calibration equations estimated $\theta_{v}$ reasonably. The $d$ values greater than 0.93 indicated good similarity between measured $\theta_{\mathrm{v}}$ and estimated $\theta_{\mathrm{v}}$ at all sites. The results showed that the best estimates of $\theta_{\mathrm{v}}$ were observed at the Bainsvlei and Mandeni sites, with $r^{2}$ values ranging from 0.96 to 0.98 and $d$-values ranging from 0.98 to 0.99 , respectively. There was a relatively lower precision at the Bronkhorstspruit site, with $r^{2}$ values ranging from 0.91 to 0.96 and RMSE values ranging from 0.012 to $0.021 \mathrm{~m}^{3} \cdot \mathrm{m}^{-3}$. The relatively lower accuracy at Bronkhorstspruit could be attributed to the presence of stones at depths greater than $20 \mathrm{~cm}$, which could have resulted in voids and air gaps between the sensor and the soil, resulting in errors, as was also noted by Huang et al. (2004). Moreover, the presence of stones in core samples could have resulted in errors in $\theta_{v}$ derived through the gravimetric technique which was used as a reference in this study, as also noted by
Kassaye et al. (2019). The sensing radius of the DFM capacitance probe is $10 \mathrm{~cm}$ (DFM Software Solutions, 2015). Consequently, gravimetric samples taken beyond the sphere of influence of the probe (approximately $30 \mathrm{~cm}$ ) might not have truly represented the soil moisture content at the probe as a result of high spatial variability of soil moisture, particularly in heterogeneous soils.

Previous studies showed that the accuracy of capacitance-based sensors is influenced by soil properties such as soil texture, $\rho_{\mathrm{d}}$, mineralogy, salinity, temperature and OC (Huang et al., 2004; Kizito et al., 2008; Fares et al., 2011; Ojo et al., 2015a; Matula et al., 2016; Bello et al., 2019; Dhakal et al., 2019; Hajdu et al., 2019). Among these soil properties, $\rho_{\mathrm{d}}$ and clay content were the most relevant to the findings of this study. The results of this study showed that relatively lower precisions were observed when $\rho_{\mathrm{d}}$ values were greater than $1.8 \mathrm{~g} \cdot \mathrm{cm}^{-3}$ at the Bronkhorstspruit site. Consequently, the accuracy of $\theta_{\mathrm{v}}$ estimation decreased with soil depth as $\rho d$ values increased with depth at Bronkhorstspruit. These findings are in agreement with the study of Huang et al. (2004), who reported that $\theta_{\mathrm{v}}$ estimated using capacitance-based sensors deviated from $\theta_{\mathrm{v}}$ measurements at greater bulk densities. The accuracy of $\theta_{\mathrm{v}}$ estimation decreased with soil depth as clay content increased at all sites, as also noted by Hajdu et al. (2019).

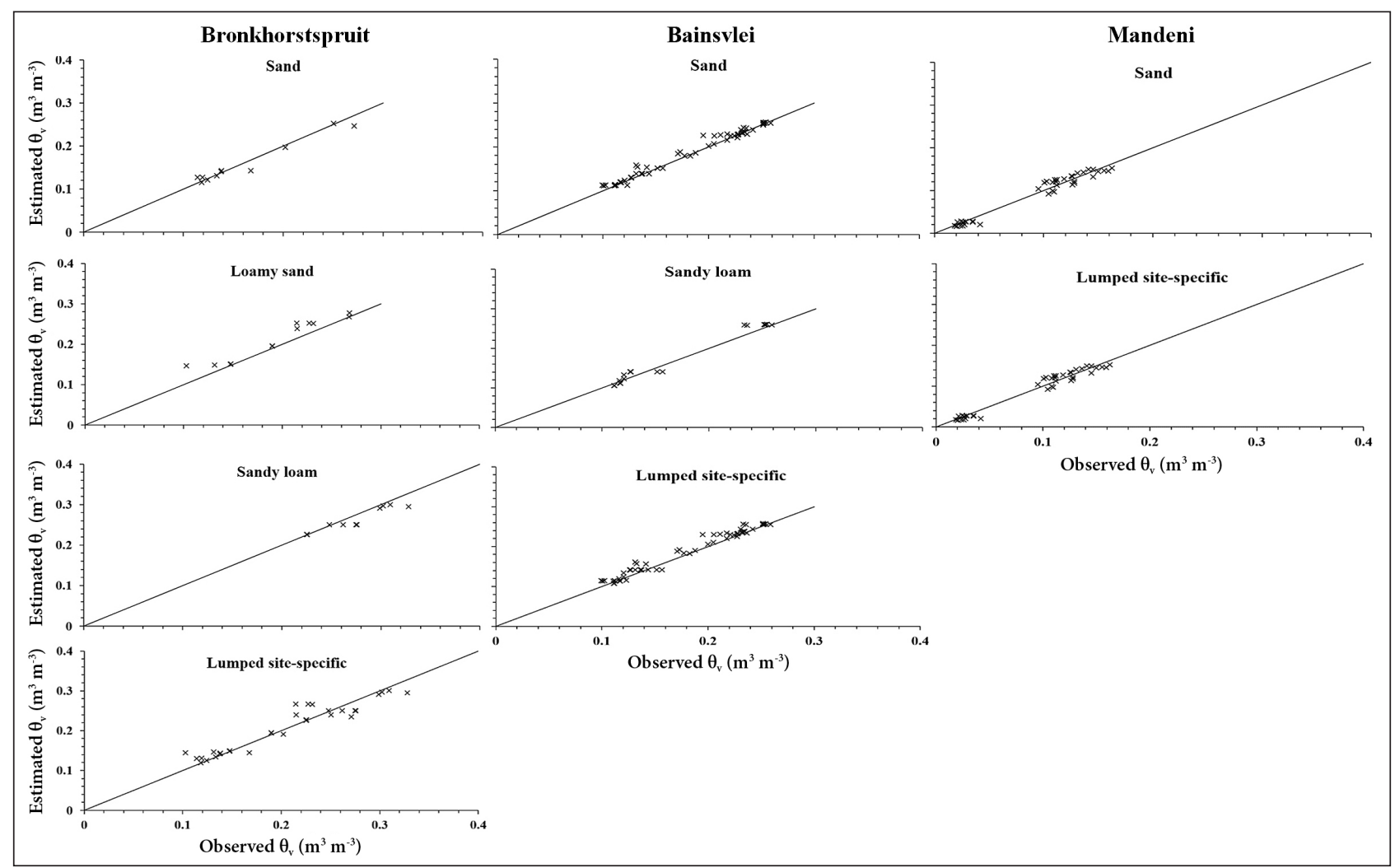

Figure 4. Validation of textural and lumped site-specific calibration equations of DFM capacitance probes at all three study sites

Table 4. Statistical results for the validation of the textural and lumped site-specific calibration equations of DFM capacitance probes at all three sites

\begin{tabular}{lcccccccc}
\hline Site & Textural class & $\boldsymbol{n}$ & $\begin{array}{c}\mathrm{RMSE} \\
\left(\mathrm{m}^{3} \cdot \mathrm{m}^{-3}\right)\end{array}$ & $\begin{array}{c}\mathrm{MBE} \\
\left(\mathrm{m}^{3} \cdot \mathrm{m}^{-3}\right)\end{array}$ & $\begin{array}{c}\mathrm{m} \\
\left(\mathrm{m}^{3} \cdot \mathrm{m}^{-3}\right)\end{array}$ & $\begin{array}{c}\mathrm{C} \\
\left(\mathrm{m}^{3} \cdot \mathrm{m}^{-3}\right)\end{array}$ & $r^{2}$ & $d$ \\
\hline Bainsvlei & Sand & 42 & 0.011 & 0.004 & 0.951 & 0.014 & 0.97 & 0.98 \\
& Sandy loam & 23 & 0.012 & 0.005 & 1.050 & 0.003 & 0.98 & 0.99 \\
& Lumped site-specific & 65 & 0.020 & 0.012 & 0.992 & 0.008 & 0.97 & 0.99 \\
\hline Bronkhorstspruit & Sand & 12 & 0.012 & -0.003 & 0.880 & 0.017 & 0.96 & 0.98 \\
& Loamy sand & 12 & 0.018 & 0.016 & 0.934 & 0.029 & 0.93 & 0.93 \\
& Sandy loam & 12 & 0.015 & -0.010 & 0.774 & 0.051 & 0.91 & 0.95 \\
& Lumped site-specific & 36 & 0.020 & 0.002 & 0.8642 & 0.030 & 0.91 & 0.98 \\
\hline Mandeni & Sand & 40 & 0.010 & -0.001 & 1.020 & 0.003 & 0.96 & 0.99 \\
& Lumped site-specific & 40 & 0.010 & -0.001 & 1.020 & 0.003 & 0.96 & 0.99 \\
\hline
\end{tabular}


Furthermore, results confirmed that lumped site-specific calibration equations result in lower accuracy when compared to the textural site-specific calibration equations (Da Silva et al., 2007; Dhakal et al., 2019). However, the performance of the lumped site-specific calibration equations was satisfactory, with $r^{2}$ values ranging from 0.91 to 0.97 and RMSE values ranging from 0.010 to $0.020 \mathrm{~m}^{3} \cdot \mathrm{m}^{-3}$. The $d$ values greater than 0.98 indicated a very good similarity between measured and estimated $\theta_{\mathrm{v}}$ from lumped sitespecific calibration equations at all sites. The findings of this study suggest that textural site-specific calibration equations should be given preference over lumped site-specific calibrations for accurate monitoring of $\theta_{\mathrm{v}}$ using DFM capacitance probes. The findings of this study are in agreement with the previous studies which demonstrated the need for textural-specific calibration to attain more accurate soil moisture measurements when using multidepth capacitance sensors (Huang et al., 2004; Evett et al., 2006; Dhakal et al., 2019; Hajdu et al., 2019).

Field calibration, such as that undertaken in this study, had a limited number of measurements, was labour-intensive and exhibited some errors in heterogeneous soils as gravimetric samples were taken beyond the sphere of influence of the probes. However, previous research has shown that the accuracy of any calibration equation increases with the number of observations and the accuracy of the gravimetric samples as the reference (Kinzli et al., 2011; Bello et al., 2019; Tfwala et al., 2019a). Geesing et al. (2004), Kinzli et al. (2011), Bello et al. (2019) and Tfwala et al. (2019a) showed that laboratory equations developed using undisturbed soil samples through evaporative desorption procedure and continuous measurements of weight loss of the soil cores were more accurate than field calibrations. Some of these observations were due to the colocation, as the sensor readings were recorded on the same soil volume that was weighed for $\theta_{\mathrm{g}}$. Therefore, laboratory equations developed using undisturbed soil samples may provide a suitable alternative methodology that is more reliable, with lower labour requirements for calibration of capacitance-based sensors (Bello et al., 2019; Hajdu et al., 2019; Tfwala et al., 2019a). However, laboratory facilities are costly, and transporting and soil sampling of undisturbed core samples for laboratory studies may alter the soil properties (Tfwala et al., 2019a).

The findings of our study indicated that the RMSE values of all developed textural and lumped site-specific calibration equations were within the acceptable levels of accuracy $\left(<0.04 \mathrm{~m}^{3} \cdot \mathrm{m}^{-3}\right)$ required for calibration and validation of soil moisture estimates from remote sensing and hydrological models (Rowlandson et al., 2013; Ojo et al., 2015b). Therefore, the results of this study indicated that the field calibration methodology undertaken in this study, which is cheaper and less time-consuming, is adequate for calibration of DFM capacitance probes. Furthermore, the findings of this study suggest that once DFM capacitance probes are calibrated per site, they can be reliably used for accurate in-situ soil moisture measurements in different agro-climatic conditions of South Africa, to support validation and verification of soil moisture estimates. The findings of this study are in agreement with previous studies which demonstrated that field calibration equations developed with numerous gravimetric samples at different soil moisture contents give acceptable levels of accuracy (Kaleita et al., 2005; Qi and Helmers, 2008; Ojo et al., 2015a; Poltoradnev et al., 2014; Hajdu et al., 2019).

The lack of site-specific calibration equations as the result of financial constraints limits the use of collected data for verification of remote-sensing products and hydrological models in this region (Myeni et al., 2019). The proposed field calibration methodology can be reliably used to correct datasets that have been collected over years by soil moisture sensors that have been deployed in monitoring networks without prior site-specific calibrations in this region.

\section{CONCLUSIONS}

This study aimed to optimize the accuracy of DFM capacitance probes within the framework of the ARC monitoring network to ensure high-quality soil moisture measurements. The study was undertaken to develop textural and lumped site-specific calibration equations for DFM capacitance probes, and to evaluate the accuracy levels of the developed calibration equations for continuous soil moisture monitoring in three selected soil types, under different agro-climatic conditions of South Africa. The results indicated that all developed textural and lumped site-specific calibration equations were linear functions. They also indicated that all developed calibration equations estimated $\theta_{\mathrm{v}}$ reasonably, although a relatively lower precision was observed at the Bronkhorstspruit site as a result of the presence of stones, which resulted in voids and air gaps between the sensor and the soil. The best estimations of $\theta_{v}$ were observed at the Mandeni and Bainsvlei sites. The results also showed that lumped site-specific calibration equations resulted in a lower accuracy compared to the textural site-specific calibration equations. However, the performance of lumped site-specific calibrations was satisfactory at all sites. The results indicated that textural site-specific calibration equations should be given preference over lumped site-specific calibrations to attain more accurate $\theta_{\mathrm{v}}$ measurements when using DFM capacitance probes.

This study showed that the DFM capacitance probes require calibration for different soil types to attain accurate soil moisture measurements. Therefore, this study is expected to raise awareness among probe users regarding the potential errors and implications attributed to the use of the DFM capacitance probes without any calibrations. The results of this study indicated that the field calibration methodology undertaken in this study, which is cheaper and less time-consuming than traditional field calibration techniques is adequate for calibration of DFM capacitance probes. Furthermore, the findings of this study suggest that once DFM capacitance probes have been calibrated per site, they can be reliably used for accurate in-situ soil moisture measurements in different agro-ecological conditions of South Africa, to support validation and verification of soil moisture estimates.

\section{AUTHOR CONTRIBUTIONS}

Conceptualization, L Myeni and ME Moeletsi; methodology, L Myeni, AD Clulow and ME Moeletsi; data analysis L Myeni, original draft preparation and writing, L Myeni; review and editing, L Myeni, AD Clulow and ME Moeletsi; supervision, ME Moeletsi and AD Clulow.

\section{ACKNOWLEDGMENTS}

Financial support from the Agricultural Research Council (ARC), the European Union's Horizon 2020 research and innovation programme under Grant Agreement No. 727201, the University of KwaZulu-Natal and National Research Foundation is gratefully acknowledged. Dr Thandile Mdlambuzi (ARC) is gratefully acknowledged for his technical support during fieldwork. We also thank Dr Zaid Bello (University of the Free State) and Dr Thomas Fyfield (ARC) for proof-reading and editing the manuscript.

\section{REFERENCES}

ALBERGEL C, DE ROSNAY P, GRUHIER C, MUÑOZ-SABATER J, HASENAUER S, ISAKSEN L, KERR Y and WAGNER W (2012) Evaluation of remotely sensed and modelled soil moisture products using global ground-based in situ observations. Remote Sens. Environ. 118 215-226. https://doi.org/10.1016/j.rse.2011.11.017

AMRI R, ZRIBI M, LILI-CHABAANE Z, WAGNER $\mathrm{W}$ and HASENAUER S (2012) Analysis of C-band scatterometer moisture estimations derived over a semiarid region. IEEE Trans. Geosci. Remote Sens. 50 (7) 2630-2638. https://doi.org/10.1109/TGRS.2012. 2186458 
ARCHER NAL, RAWLINS BR, MACHANT BP, MACKAY JD and MELDRUM PI (2016) Approaches to calibrate in-situ capacitance soil moisture sensors and some of their implications. SOIL Discussions 1-29. https://www.soil-discuss.net/soil-2016-40/soil2016-40.pdf (Accessed 1 April 2019).

BELLO ZA, TFWALA CM and VAN RENSBURG LD (2019) Evaluation of newly developed capacitance probes for continuous soil water measurement. Geoderma. 345 (1) 104-113. https://doi.org/10.1016/j. geoderma.2019.03.030

BOGENA HR, HUISMAN JA, SCHILLING B, WEUTHEN A and VEREECKEN H (2017) Effective calibration of low-cost soil water content sensors. Sensors. 17 (1) 208-220. https://doi.org/10.3390/ s17010208

BROCCA L, CIABATTA L, MASSARI C, CAMICI S and TARPANELLI A (2017) Soil moisture for hydrological applications: Open questions and new opportunities. Water. 9 (2) 140-160. https://doi.org/10.33 90/w9020140

COBOS DR and CHAMBERS C (2010) Calibrating ECH2O soil moisture sensors, application note. http://cn.ictinternational.com/content/ uploads/2014/03/13393-04 CalibratingECH2OSoilMoistureProbes. pdf (Accessed 15 April 2019).

CONRADIE DC (2012) South Africa's climatic zones: today, tomorrow. URL: http://researchspace.csir.co.za/dspace/handle/10204/6064 (Accessed 18 August 2018).

DA SILVA CR, DE ANDRADE JÚNIOR AS, ALVES JÚNIOR J, DE SOUZA AB, DE BRITO MELO F and COELHO FILHO MA (2007) Calibration of a capacitance probe in a Paleudult. Sci. Agric. 64 (6) 636-640. https://doi.org/10.1590/s0103-90162007000600012

DFM SOFTWARE SOLUTIONS (2015) Introduction to DFM Software. http://www.dfmsoftware.co.za (Accessed 25 February 2019).

DHAKAL M, WEST CP, DEB SK, KHAREL G and RITCHIE GL (2019) Field Calibration of PR2 Capacitance Probe in Pullman Clay-Loam Soil of Southern High Plains. Agrosyst. Geosci. Environ. 2 (1) 1-7. https://doi.org/10.2134/age2018.10.0043

DIAMOND HJ, KARL TR, PALECKI MA, BAKER CB, BELL JE, LEEPER RD, EASTERLING DR, LAWRIMORE JH, MEYERS TP and HELFERT MR (2013) US Climate Reference Network after one decade of operations: Status and assessment. Bull. Am. Meteorol. Soc. 94 (4) 485-498. https://doi.org/10.1175/BAMS-D-12-00170.1

DOBRIYAL P, QURESHI A, BADOLA R and HUSSAIN SA (2012) A review of the methods available for estimating soil moisture and its implications for water resource management. J. Hydrol. 458 (1) 110-117. https://doi.org/10.1016/j.jhydrol.2012.06.021

DORIGO W, GRUBER A, VAN OEVELEN P, WAGNER W, DRUSCH M, MECKLENBURG S, ROBOCK A and JACKSON T (2011) The international soil moisture network - An observational network for soil moisture product validations. $34^{\text {th }}$ International Symposium on Remote Sensing of Environment - The GEOSS Era: Towards Operational Environmental Monitoring 2-5. URL: https://www. isprs.org/proceedings/2011/isrse-34/211104015Final00819.pdf (Accessed 26 February 2019).

ERSAHIN S, GUNAL H, KUTLU T, YETGIN B and COBAN S (2006) Estimating specific surface area and cation exchange capacity in soils using fractal dimension of particle-size distribution. Geoderma. 136 (3-4) 588-597. https://doi.org/10.1016/j.geoderma.2006.04.014

EVETT SR, TOLK JA and HOWELL TA (2006) Soil profile water content determination. Vad. Zone J. 5 (3) 894-907. https://doi.org/10.2136/ vzj2005.0149

FARES A, ABBAS F, MARIA D and MAIR A (2011) Improved calibration functions of three capacitance probes for the measurement of soil moisture in tropical soils. Sensors. 11 (5) 4858-4874. https://doi.org/ $10.3390 / \mathrm{s} 110504858$

GABRIEL JL, LIZASO JI and QUEMADA M (2010) Laboratory versus field calibration of capacitance probes. Soil Sci. Soc. Am. J. 74 (2) 593-601. https://doi.org/10.2136/sssaj2009.0157

GEE GW and BAUDER JW (1986) Particle-size analysis. In: Klute A (ed.) Methods of Soil Analysis. Part 1. Physical and Mineralogical Methods. SSSA Book Ser. 5. SSSA, Madison, WI. 383-411. https:// doi.org/10.2136/sssabookser5.1.2ed.c15

GEESING D, BACHMAIER M and SCHMIDHALTER U (2004) Field calibration of a capacitance soil water probe in heterogeneous fields. Australian Journal of Soil Research. 42 (3) 2 https://doi.org/10.1071/ SR03051
GRUBER A, DORIGO WA, ZWIEBACK S, XAVER A and WAGNER W (2013) Characterizing coarse-scale representativeness of in situ soil moisture measurements from the international soil moisture network. Vadose Zone Journal. 12 (2) 1-16. https://doi.org/10.2136/ vzj2012.0170

GRUHIER C, DE ROSNAY P, HASENAUER S, HOLMES T, DE JEU R, KERR Y, MOUGIN E, NJOKU EG, TIMOUK F and WAGNER W (2010) Soil moisture active and passive microwave products: intercomparison and evaluation over a Sahelian site. Hydrol. Earth Syst. Sci. 14 141-156. https://doi.org/10.5194/hess-14-141-2010

HAJDU I, YULE I, BRETHERTON M, SINGH R and HEDLEY C (2019) Field performance assessment and calibration of multidepth AquaCheck capacitance-based soil moisture probes under permanent pasture for hill country soils. Agric. Water Manage. 217 (1) 332-345. https://doi.org/10.1016/j.agwat.2019.03.002

HOLZMAN M, RIVAS R, CARMONA F and NICLÒS R (2017) A method for soil moisture probes calibration and validation of satellite estimates. MethodsX. 4 (1) 243-249. https://doi.org/10.1016/ j.mex.2017.07.004

HUANG Q, AKINREMI OO, SRI RAJAN R and BULLOCK P (2004) Laboratory and field evaluation of five soil water sensors. Can. J. Soil Sci. 84 (4) 431-438. https://doi.org/10.4141/S03-097

IUSS WORKING GROUP (2014) World Reference Base for soil resources 2014: international soil classification system for naming soils and creating legends for soil maps. World Soil Resources Report. 106. URL: http://www.fao.org/3/i3794en/I3794en.pdf (Accessed 28 May 2019).

KALEITA AL, HEITMAN JL and LOGSDON SD (2005) Field calibration of the Theta Probe for Des Moines lobe soils. Appl. Eng. Agric. 21 (5) 865-870. https://doi.org/10.13031/2013.19714

KASSAYE KT, BOULANGE J, SAITO H and WATANABE H (2019) Calibration of capacitance sensor for Andosol under field and laboratory conditions in the temperate monsoon climate. Soil Tillage Res. 189 (1) 52-63. https://doi.org/10.1016/j.still.2018.12.020

KINZLI K-D, MANANA N and OAD R (2011) Comparison of laboratory and field calibration of a soil-moisture capacitance probe for various soils. J. Irrig. Drainage Eng. 138 (4) 310-321. https://doi. org/10.1061/(asce)ir.1943-4774.0000418

KIZITO F, CAMPBELL CS, CAMPBELL GS, COBOS DR, TEARE BL, CARTER B and HOPMANS JW (2008) Frequency, electrical conductivity and temperature analysis of a low-cost capacitance soil moisture sensor. J. Hydrol. 352 (3-4) 367-378. https://doi. org/10.1016/j.jhydrol.2008.01.021

MATULA S, BÁT'KOVÁ K and LEGESE WL (2016) Laboratory performance of five selected soil moisture sensors applying factory and own calibration equations for two soil media of different bulk density and salinity levels. Sensors. 16 (11) 192-214. https://doi. org/10.3390/s16111912

MJANYELWA N, BELLO ZA, GREAVES W and VAN RENSBURG LD (2016) Precision and accuracy of DFM soil water capacitance probes to measure temperature. Comput. Electron. Agric. 125 (1) 125-128. https://doi.org/10.1016/j.compag.2016.04.027

MOELETSI ME, MABUZA B and BEUKES D (2009) Soil water content measurement and archiving for potential use in agriculture. Agricultural Research Council - Institute for Soil, Climate and Water. Unpublished report, Project No. GW52/081, Pretoria, South Africa.

MYENI L, MOELETSI ME and CLULOW AD (2019) Present status of soil moisture estimation over the African continent. J. Hydrol.: Reg. Stud. 21 (1) 14-24. https://doi.org/10.1016/j.ejrh.2018.11.004

OJO ER, BULLOCK PR and FITZMAURICE J (2015a) Field performance of five soil moisture instruments in heavy clay soils. Soil Sci. Soc. Am. J. 79 (1) 20-29. https://doi.org/10.2136/sssaj2014.06.0250

OJO ER, BULLOCK PR, L'HEUREUX J, POWERS J, MCNAIRN H and PACHECO A (2015b) Calibration and evaluation of a frequency domain reflectometry sensor for real-time soil moisture monitoring. Vadose Zone Journal. 14 (3) 1-12. https://doi.org/10.2136/vzj2014.08. 0114

PAN W, BOYLES RP, WHITE JG and HEITMAN JL (2012) Characterizing soil physical properties for soil moisture monitoring with the North Carolina environment and climate observing network. J. Atmos. Oceanic Technol. 29 (7) 933-943. https://doi.org/ 10.1175/JTECH-D-11-00104.1 
PARASKEVAS C, GEORGIOU P, ILIAS A, PANORAS A and BABAJIMOPOULOS C (2012) Calibration equations for two capacitance water content probes. Int. Agrophys. 26 (3) 285-293. https://doi.org/10.2478/v10247-012-0041-7

PARVIN N and DEGRÉ A (2016) Soil-specific calibration of capacitance sensors considering clay content and bulk density. Soil Res. 54 (1) 111-119. https://doi.org/10.1071/sr15036

PEGRAM GGS, SINCLAIR S, VISCHEL T and NXUMALO N (2010) Soil moisture from satellites: daily maps over rsa for flash flood forecasting, drought monitoring, catchment management \& agriculture. WRC Report No. K5/2335. Water Research Commission, Pretoria. http://www.wrc.org.za/Knowledge\%20Hub\%20Documents/ Research\%20Reports/1683-1-10.pdf (Accessed 5 July 2018).

POLTORADNEV M, INGWERSEN J and STRECK T (2014) Calibration and application of Aquaflex TDT soil water probes to measure the soil water dynamics of agricultural topsoil in southwest Germany. J. Irrig. Drainage Eng. 141 (6) 1-11. https://doi.org/10.1061/(asce) ir.1943-4774.0000838

QI Z and HELMERS MJ (2008) Field calibration of a multisensor capacitance probe for Des Moines lobe soils. https://pdfs.sem anticscholar.org/e92d/217c18a409aa4b31b9d2ec84312f7946d679.pdf (Accessed 5 June 2019).

ROETS N, CRONJE R, SCHOEMAN S, MUROVHI $\mathrm{N}$ and RATLAPANE I (2013) Calibrating avocado irrigation through the use of continuous soil moisture monitoring and plant physiological parameters. S. Afr. Avocado Growers' Assoc. Yearbook. 36 36-41.

ROWLANDSON TL, BERG AA, BULLOCK PR, OJO ERT, MCNAIRN $\mathrm{H}$, WISEMAN G and COSH MH (2013) Evaluation of several calibration procedures for a portable soil moisture sensor. J. Hydrol. 498 (1) 335-344. https://doi.org/10.1016/j.jhydrol.2013.05.021

SENEVIRATNE SI, CORTI T, DAVIN EL, HIRSCHI M, JAEGER EB, LEHNER I, ORLOWSKY B and TEULING AJ (2010) Investigating soil moisture-climate interactions in a changing climate: A review. Earth-Sci. Rev. 99 (3-4) 125-161. https://doi.org/10.1016/ j.earscirev.2010.02.004
SOIL CLASSIFICATION WORKING GROUP (1991) Soil classification: a taxonomic system for South Africa. Memoirs on the Agricultural Natural Resources of South Africa. 15 1-262.

TFWALA CM, VAN RENSBURG LD, BELLO ZA and ZIETSMAN PC (2019a) Laboratory vs. field calibration of HydraSCOUT probes for soil water measurement. Pedosphere. 29 (1) 132-136. https://doi.org/ 10.1016/S1002-0160(18)60060-8

TFWALA CM, VAN RENSBURG LD, BELLO ZA and ZIETSMAN PC (2019b) Transpiration dynamics and water sources for selected indigenous trees under varying soil water content. Agric. For. Meteorol. 275 (1) 296-304. https://doi.org/10.1016/j.agrformet.2019.05.030

VARBLE JL and CHÁVEZ JL (2011) Performance evaluation and calibration of soil water content and potential sensors for agricultural soils in eastern Colorado. Agric. Water Manag. 101 (1) 93-106. https://doi.org/10.1016/j.agwat.2011.09.007

WALKER JP, WILLGOOSE GR and KALMA JD (2004) In situ measurement of soil moisture: A comparison of techniques. J. Hydrol. 293 (1-4) 85-99. https://doi.org/10.1016/j.jhydrol.2004.01.008

WILLMOTT CJ, ACKLESON SG, DAVIS RE, FEDDEMA JJ, KLINK KM, LEGATES DR, O'DONNELL J and ROWE CM (1985) Statistics for the evaluation and comparison of models. J. Geophys. Res. 90 (C5) 8995-9005. https://doi.org/10.1029/jc090ic05p08995

ZERIZGHY MG, VAN RENSBURG LD and ANDERSON JJ (2013) Comparison of neutron scattering and DFM capacitance instruments in measuring soil water evaporation. Water SA. 39 (2) 183-190. https://doi.org/10.4314/wsa.v39i2.1

ZREDA M, SHUTTLEWORTH WJ, ZENG X, ZWECK C, DESILETS D, FRANZ T and ROSOLEM R (2012) COSMOS: The cosmic-ray soil moisture observing system. Hydrol. Earth Syst. Sci. 16 (11) 40794099. https://doi.org/10.5194/hess-16-4079-2012 